\title{
Effects of mucus trail following on the distance between individuals of opposite sex and its influence on the evolution of the trait in the Ezo abalone Haliotis discus hannai
}

\author{
Yukio Matsumoto ${ }^{\text {Corresp. } 1}$ \\ ${ }^{1}$ Miyako Laboratory, Tohoku National Fisheries Research Institute, Japan Fisheries Research and Education Agency, Miyako, Iwate, Japan \\ Corresponding Author: Yukio Matsumoto \\ Email address: yukio.matsumoto@live.jp
}

Background. Aggregation affects the fertilization rate of species that utilize external fertilization. However, the process of aggregation has not been studied in detail, using either theoretical models or real world observations. We used the Ezo abalone Haliotis discus hannai as a model animal species to evaluate whether mucus trail following (MTF) facilitates aggregation by reducing the distance between members of opposite sexes. We also examined whether the fertilization rate increase with mucus-trailfollowing is an evolutionary driving force in mucus following behavior.

Methods. We used a y-maze to test whether $H$. discus hannai follows the mucus trails of other individuals. Distances between members of the opposite sex of MTF individuals were compared to nonMTF individuals using an individual-based model (IBM) consistent with the behavior of $H$. discus hannai. To examine whether MTF behavior evolved to reduce distances between members of the opposite sex, we constructed simple population genetic models of a diploid population with nonoverlapping, discrete generations.

Results. Haliotis discus hannai chose the y-maze arm with the mucus trail more frequently than the one without, regardless of the sex of the abalone that secreted the mucus or the reproductive season. In the IBM the distance between opposite sexes was significantly reduced by MTF behavior; however, the difference in distances between opposite sex compared to same sex individuals was only several centimeters. Simple population genetic models indicated that the aggregating effect of MTF between the opposite sex members could be an evolutionary driving force.

Conclusions. These results suggest that observed MTF behavior might have evolved as a mechanism to increase the fertilization rates although other factors could also be involved. 


\section{Effects of mucus trail following on the distance between}

2 individuals of opposite sex and its influence on the evolution

3 of the trait in the Ezo abalone Haliotis discus hannai

4

5

6 Yukio Matsumoto ${ }^{1}$

7 'Miyako Laboratory, Tohoku National Fisheries Research Institute, Japan Fisheries Research and

8 Education Agency, Miyako, Iwate, Japan

9

10
Corresponding Author: Yukio Matsumoto1

Sakiyama 4-9-1, Miyako, Iwate 027-0097, Japan

Email address: ymatsumoto@affrc.go.jp
Abstract

Background. Aggregation affects the fertilization rate of species that utilize external fertilization. However, the process of aggregation has not been studied in detail, using either theoretical models or real world observations. We used the Ezo abalone Haliotis discus hannai as a model animal species to evaluate whether mucus trail following (MTF) facilitates aggregation by reducing the distance between members of opposite sexes. We also examined whether the fertilization rate increase with mucus-trail-following is an evolutionary driving force in mucus following behavior.

Methods. We used a y-maze to test whether H. discus hannai follows the mucus trails of other individuals. Distances between members of the opposite sex of MTF individuals were compared to non-MTF individuals using an individual-based model (IBM) consistent with the behavior of H. discus hannai. To examine whether MTF behavior evolved to reduce distances between members of the opposite sex, we constructed simple population genetic models of a diploid population with nonoverlapping, discrete generations.

Results. Haliotis discus hannai chose the y-maze arm with the mucus trail more frequently than the one without, regardless of the sex of the abalone that secreted the mucus or the reproductive 
30

31

32

33

34

35

36

37

38

39

40

41

42

43

44

45

46

47

48

49

50

51

52

53

54

55

56

57

58

59

season. In the IBM the distance between opposite sexes was significantly reduced by MTF behavior; however, the difference in distances between opposite sex compared to same sex individuals was only several centimeters. Simple population genetic models indicated that the aggregating effect of MTF between the opposite sex members could be an evolutionary driving force.

Conclusions. These results suggest that observed MTF behavior might have evolved as a mechanism to increase the fertilization rates although other factors could also be involved.

\section{Introduction}

Studies of the Allee effect in externally fertilized species are important for population management because a decreasing density of adults decreases the fertilization rate, potentially to the point of population collapse (Berec, Angulo \& Courchamp, 2007). Previous studies indicated that water flow (Babcock \& Keesing, 1999), spawning synchrony (Calabrese \& Fagan, 2004), and the distance between opposite sexes (Babcock \& Keesing, 1999; Levitan, Sewell \& Chia, 2016) affect egg fertilization. Although the distance between individuals of opposite sex decreases naturally with increasing population density, distance can also decrease because of aggregation behavior. Theoretical models including aggregation behavior demonstrate higher rates of fertilization compared to those without at the same population density (Claereboudt, 1999; Lundquist \& Botsford, 2004; Zhang, 2008). However, the mechanism underlying aggregation has not been widely studied across multiple species or through theoretical models. The cues used by individuals to recognize the opposite sex will affect the distance over which they can respond. For example, when individuals visually recognize others the encounter rate is low at low population densities; whereas if individuals recognize each other through olfaction they can search for the opposite sex from a distant location (Jumper \& Baird, 1991). Although a model has been developed that considers the distance over which individuals can recognize the opposite sex (Baird \& Jumper, 1995; Coates \& Hovel, 2014), the cues used by animals for recognition remains unclear.

It has been reported that gastropod species follow mucus trails for mate searching, as they prefer to follow mucus from the same species (Nakashima, 1995) and from the opposite sex (Erlandsson \& Kostylev, 1995; Johannesson et al., 2010; Ng et al., 2011). However, the extent to which the efficiency of mate searching is increased by mucus trail following (MTF) has not been 
60

61

62

63

64

65

66

67

68

69

70

71

72

73

74

75

76

77

78

79

80

81

82

83

84

85

86

87

88

89

tested. In addition, it is noteworthy that the reproductive success of individuals that do not follow mucus trails could increase when they are followed by the mucus-following individuals that follow the mucus. This phenomenon should be considered in the evolutionary process of MTF behavior. In the earlier stages of a trait's evolution it is generally assumed that a small number of individuals with the trait (i.e. mutant type) occur within a population without the trait (wild type): when the mutant type leaves relatively more offspring than the wild type its frequency should increase. When applying this conceptual framework to the evolution of MTF, it is assumed animals that follow mucus trails (i.e. mutant type) and those that do not (i.e. wild type) have coexisted. In this situation, the reproductive success of the wild type could be increased when the mutant type follows the mucus of the wild type. In other words, as the difference in fitness between mutant type and wild type might be small, the greater efficiency in mate searching might not be the evolutionary driving force of MTF behavior.

In Haliotis species, which uses external fertilization, aggregation and distance between opposite sexes have been investigated as the index indicating the encounter of opposite sex members (e.g., Button, 2008). The current study was conducted to test the relationship between MTF and distance between opposite sexes using H. discus hannai as the model animal. First, we confirmed that $H$. discus hannai exhibits non-self MTF behavior. Next, we tested whether MTF reduces the distance between opposite sexes. One way to examine the effect of MTF on mate searching is by comparing the distances between opposite sex individuals that exhibit MTF and those that do not. Non-mucus following individuals were obtained by excision of the cephalic tentacle, the sensory organ that detects mucus in Haliotis species (Kuanpradit et al., 2012). However, it is highly possible that such an invasive procedure causes subsequent abnormal behavior. We therefore created an Individual Based Model (IBM) in which some individuals exhibited MTF behavior and some did not. We analysed this model to test whether reduced distances between opposite sexes is an evolutionary driving force of MTF behavior.

\section{Materials \& Methods}

\section{Study species}

7 Haliotis discus species is a marine gastropod mollusk in the family Haliotidae, which is 8 distributed in the waters off Japan and eastern Asia. The species mainly inhabits rocky shores.

89 The spawning season in the Iwate Prefecture, Japan, is from August to late October, when water 
90 temperatures are around $20-21^{\circ} \mathrm{C}$ after the effective accumulated temperature (EAT; Uki \& 91 Kikuchi, 1984) reaches 1000 degree-days. Experimental animal subjects were captured in the

92 93

94 95 96

ocean of Iwate Prefecture in October 2015 and segregated by gender in tanks equipped with water temperature control.

\section{Mucus trail following}

To evaluate whether $H$. discus hannai follows mucus trails, binary choice tests were conducted using a y-maze, taking place on December 11-28, 2015, August 17-20, 2016, and June 26-July 17, 2017. In this study, individuals with immature gonads were classed as non-reproductive individuals (experiments conducted during December 11-28, 2015) and individuals at simulated EAT 1000-2000 degree-days were classed as reproductive individuals (experiments conducted during August 17-20, 2016, and June 26-July 17, 2017). The y-maze consisted of a 50-cm stem and $50-\mathrm{cm}$ arms (width, $9 \mathrm{~cm}$; height, $5 \mathrm{~cm}$ ). Further details of the experimental abalones are presented in Supplemental data S1. The experiments were conducted as follows.

Step 1: To form the mucus trail on the surface of the y-maze, one arm of the y-maze was closed using a plastic plate, thus restricting where marker individuals were allowed to move (right arm: $\mathrm{n}=38$, left arm: $\mathrm{n}=37$ ). The marker individual was released at the end of the stem in the daytime and usually began moving within one hour, eventually reaching the end of the y-maze arm after which is was removed. The plastic plate was then removed to open both arms of the ymaze. If the marker individual remained at the end of the stem for over a day they were replaced with a new marker individual.

Step 2: The subject individual was released at the end of the stem and its direction of creeping was observed. This step commenced at 18:00 h because $H$. discus hannai individuals are active after sunset. Followers often reached the end of the arms within several minutes. If a follower remained at the end of the stem for over $30 \mathrm{~min}$, its direction of creeping was observed using a video camera (DVSA10FHDIR; Kenko Tokina Corporation, Tokyo, Japan) until 6:00 h. If a follower individual remained at the end of the stem for over a day, the experiment was stopped. After finishing each experiment, the walls and floor of the y-maze were scrubbed clean using a spongy, prior to beginning subsequent experiments. 
The effects of marker-tracker combinations and season on MTF rates were tested using a generalized liner model (binomial distribution) with likelihood ratio tests using the "Anova" function in the "car" package for R v3.5.2. We also used a binomial test to determine whether MTF was actually being observed, without dividing the subjects into experimental groups.

Mucus trail following as a mate-finding strategy

To examine whether MTF behavior reduces the distance between members of the opposite sex, an IBM consistent with the behavior of $H$. discus hannai was constructed (see also Supplemental Fig. S1) using NetLogo v5.3.1. The script is available on GitHub with the following file name: Supplemental file S1 (https://github.com/YMatsumoto5536/PeerJ-netlogo).

In this model, female MTF abalones (i.e. mutant females), and non-MTF female and male abalones (wild females and wild males) were generated. The IBM compared the distances between wild males and mutant females and between the wild males and wild females. The comparison revealed whether MTF is effective for reducing the distances between the members of the opposite sex from the aspect of female benefit.

Spatial units and time scale of the model: The density of $H$. discus hannai varies by year and location within the Iwate Prefecture; the observed density ranges from 0.56 to 3.82 individuals $\mathrm{m}^{-2}$ (Ohmura et al., 2015), with a range of 1.0-1.5 individuals $\mathrm{m}^{-2}$ occurring most frequently. We therefore implemented an abalone density of 1.0 individual $\mathrm{m}^{-2}$ in the model. Spatial units were $10 \mathrm{~cm} \times 10 \mathrm{~cm}$ grid cells and the model consisted of a $3 \mathrm{~m}^{2}$ area (i.e. $30 \times 10$ grid cells). The boundaries of the model world were reflective: when individuals reached a boundary, they turned $90^{\circ}$ and resumed movement in the new direction. Each time step represented one day and the models were run for 30 steps (i.e. 30 days).

Movement algorithm: Mutant females searched the grid for a mucus trail within a $10 \mathrm{~cm}$ search radius. They next decide whether to move to a grid cell with mucus or an empty grid cell according to their individual mucus following rate parameter (see below). The individual moving distance for each day was generated from an exponential distribution with mean of $48.76 \mathrm{~cm}$, which is consistent with observed behavior in the holding tanks (Supplemental data S2). The individual MTF rate was generated from a binomial distribution (trial number $=75$, number of arms with mucus $=60$, estimated following rate $=0.8$ ). This following rate is consistent with the 
147 observed behavior in the tank experiments (Fig. 1). Model abalones followed mucus trails

148 irrespective of the sex combination, consistent with the only small sex combination effects

149 observed in the tank experiment (Fig.1). Although the wild females and wild males moved the

150 same distance as the mutant females, their direction of movement was random. All individuals

151 left mucus trails before moving to the next grid cell. Studies have suggested that the mucus trail

152 of gastropods is degraded by bacteria within a single day (Herndl \& Peduzzi, 1989; Peduzzi \&

153 Herndl, 1991). Therefore, we set the functional persistence period of the mucus to one day in the

154 IBM. These processes were repeated until the day's determined locomotion distance had been

155 reached. At the end of the 30 day test period the distances between opposite sex individual was

156 measured.

157 Measuring the distance between opposite sex members: Differences in the distances between

158 mutant females and wild females were compared using a generalized liner mixed model

159 (Gaussian distribution) using the "Imer" function in the "Ime4" package for R v3.5.2. To conduct

160 paired comparisons within simulations, the simulation number was treated as a random-intercept

161 in the model. The effects of locomotion type on the nearest neighbor distance were tested with

162 likelihood ratio tests using the "Anova" function in the "car" package.

163 Evolutionary model of MTF behavior

164 To examine whether abalones evolved the ability to follow mucus trails to reduce distances

165 between members of the opposite sex, we constructed simple population genetic models for a

166 diploid population undergoing nonoverlapping, discrete generations (see also Supplemental Fig.

167 S2). It should be noted, however, that $H$. discus hannai undergoes repeated spawning over

168 several years. The script is available on GitHub with the following file name: Supplemental file

169 S2 (https://github.com/YMatsumoto5536/PeerJ-netlogo).

170 Dynamics of allele frequency: In MTF model, the MTF mutant type and non-MTF wild type

171 were evaluated for a single autosomal locus with two alleles, dominant $(D)$ and recessive $(d)$. $D D$

172 and $D d$ individuals both followed the mucus trail (to the same extent), while $d d$ individuals did

173 not. The behavioral rules of mutant type and wild-type were otherwise the same as in the model

174 described above. After the model was run for 30 days the nearest neighbor distances between

175 members of the opposite sex were measured. Each female fertilized its eggs with the nearest 
176 males. The number of eggs was determined using the following equation: the number of 177 fertilized eggs $=88.31^{-0.32 \times \text { distance, }}$, as described by Babcock \& Keesing (1999). The rate of 178 mutant type and wild-type in the next generation $(n+1)$ with a population size of 10,000 was 179 determined based on the ratio of the number fertilized eggs of each type in the current generation 180 (n). This cycle was repeated for 2000 generations and the frequency of each allele was assessed.

181 Population size: The effective real world population size $\left(\mathrm{N}_{e}\right)$ of $H$. discus hannai is not clear.

182 We thus set the population size to 10000 because beneficial traits are removed by random 183 genetic drift processes when the population size is small. A control model in which $D D$ and $D d$ 184 individuals did not follow mucus trail was constructed to confirm that the random genetic drift 185 had little effect on the allele frequency in the MTF model. At the start of each simulation, 9980 individuals with $d d$ (wild type) and 20 individuals $D d$ (mutant) were generated, assigned with a sex ratio of 1:1. Individuals were distributed randomly across a $10000 \mathrm{~m}^{2}$ grid $\left(1000 \times 10001 \mathrm{~m}^{2}\right.$ 188 grid cells).

189

190

191

192

193

194

195

196

197

198

199

200

201

202

203

204

\section{Results}

\section{Following the mucus trail of another individual}

The MTF rates observed in each experiment are shown in Figure. 1. The marker and follower combinations (likelihood-ratio test, $d f=4, \chi^{2}=2.68, p=0.61$ ), season $\left(d f=1, \chi^{2}=0.026, p=\right.$ $0.87)$, and their interaction term $\left(d f=3, \chi^{2}=0.36, p=0.95\right)$ did not affect the MTF rate. Abalones chose the arm with a mucus trail more frequently $(n=60)$ than the arm without a mucus trail $(\mathrm{n}=15)$ when experimental groups were pooled (binomial test, $p=1.588 \mathrm{e}-07)$.

\section{MTF reduces the distance between opposite sex individuals}

The distance between wild males and mutant females (mean $\pm \mathrm{SD}=10.83 \pm 6.57 \mathrm{~cm}$ ) was significantly less than that between wild males and wild females $(11.08 \pm 6.61 \mathrm{~cm} ; d f=1, F=$ $6.90, p=0.009)$; however, the estimation difference in distance was only $2.4( \pm \mathrm{SD}=0.8) \mathrm{cm}$.

\section{Evolutionary role of reducing opposite-sex distances in MTF}

As the frequency of $D$ alleles did not increase over the generations in the control model (Fig. 2a), the increasing frequency of $D$ alleles in the trail following model was caused by an increased fertilization rate rather than random genetic drift. In the MTF model, the frequency of $D$ alleles (Fig. 2b, see also Supplemental data S3) increased over the generations 53 of the 100 
205 simulations. Complete disappearance of the $D$ allele occurred within 314 generations (average \pm $206 \mathrm{SD}=88 \pm 69$ generations; range $=13-314)$ in the MTF model.

\section{Discussion}

\section{The MTF trait}

209 Our experiments strongly suggest that the presence of a non-self mucus trail affects the 210 directional decision making in $H$. discus hannai. Mucus trails of $H$. discus hannai are known to 211 attract their larvae (Roberts, 2001); thus, it is not surprising that adult individuals also react to 212 conspecific mucus trails. The tentacles of $H$. asinina react to protein extracted from mucus trails 213 in vitro (Kuanpradit et al., 2012), further supporting the hypothesis that $H$. discus hannai senses 214 mucus trails using their tentacles.

215 We found that $H$. discus hannai followed mucus trails irrespective of the marker's sex or season. 216 As the experimental design did not allow for the selection of mucus from different sexes 217 simultaneously, we cannot deny the possibility that $H$. discus hannai might prefer mucus from 218 the opposite sex and sex-related differences in preference for mucus, although sex-related 219 differences in mucus composition have not been found in H. asinina (Kuanpradit et al., 2012). 220 Although the preference for mucus from the opposite sex in H. discus hannai was not detected in 221 this study, there remains the possibility that mucus-trail-following shorten the distance between 222 opposite sexes more efficiently than creeping without mucus-trail-following.

The factors that affect decision making about MTF should be investigated in the future, and not only the trail following rate. For instance, the trail following rate of Nodilittorina unifasciata increases when emersed during low tide (Chapman, 1998). Starvation could also affect MTF behavior because some gastropod species ingest mucus as an energy source (Davies

227 \& Beckwith, 1999; Hutchinson et al., 2007; Ng et al., 2013). Conversely, animals avoiding the trail of other animals may acquire more food than those that follow others.

229

230

231

232 233

\section{MTF reduces distances between members of the opposite sex}

Although some studies have suggested that MTF increases the efficiency of mate searching $(\mathrm{Ng}$ et al., 2013), no study has produced a definitive demonstration. Previous investigations have focused on the rate of MTF rather than the function of this behavior. In this study, we used an IBM to show that the mean distance between opposite sex individuals was significantly reduced 
234 by MTF. However, the distance between males and mutant females was greater than that 235 between males and wild females in 4907 out of 10,000 simulations. Additionally, distances can 236 be reduced when mutant females follow the mucus of wild males: in such cases the fertilization 237 rate (i.e. reproductive success) of wild males increase even though they do not themselves 238 exhibit MTF behavior.

Locomotion patterns might have affected the distances between males and females in 240 ways other than MTF in our model. The random number generated from the probability 241 distribution for the locomotion distance in H. discus hannai equated to lévy flight (Supplemental 242 Fig. S3), which is an effective searching behavior when the target is sparsely distributed (Sims et 243 al., 2012). Observed locomotion pattern in another Haliotis species was found to involve lévy 244 flight in the wild (Strain, Johnson \& Thomson, 2013); therefore, the natural locomotion pattern 245 of $H$. discus hannai might also involve lévy flight. The current study focused on MTF as a 246 method of reducing distances between members of the opposite sex; however, other behaviors 247 such as locomotion patterns should also be investigated in the future.

\section{Effect of increased fertilization rate on evolution of MTF behavior}

249 The $D$ allele increased within the population in the MTF model in just over half of the 250 simulations (53/100 simulations). This result indicates mate searching (resulting in increased 251 fertilization rates) could be the evolutionary driving force behind MTF in our model. However, 252 the $D$ allele disappeared from the population in 47 of the 100 simulations, possibly suggesting 253 that the resulting increase in fertilization rate as parameterized is not an evolutionarily stable 254 driving force in MTF. In general, changes in allele frequency depends on the product of the 255 average fitness of the phenotype and the frequency of the allele within the population (Kawata, 1989). When the fertilization rate of the mutant is lower than or almost the same as that of the wild individual, the $D$ allele disappears or does not increase at the beginning of simulations when the allele frequency is low. As described above, the observed distance between males and mutant females was greater than that of wild females in almost half of the simulations $(4907 / 10,000$ simulations): this might explain why the $D$ allele did not always increase early in the simulation. The wild type $d$ allele was not perfectly removed from the population in all simulations (Fig. 2), possibly because the fitness of followed wild individuals was increased by the MTF behavior of mutant individuals without incurring any costs. The $d$ allele might also persist in heterozygous 
$264 D d$ individuals, which express the same degree of MTF behavior as homozygous $D D$ 265 individuals.

266 As allele $D$ did not increase in about half of the simulations, other benefits in addition to 267 increased fertilization rates could be the evolutionary driving force of MTF in the real world. For 268 example, MTF reduces the energy cost for adhesion and locomotion; gastropods require energy 269 to secrete a mucus trail to adhere and move across the substrate (Davies \& Hawkins, 1998). An 270 individual following a mucus trail can decrease the amount of mucus being secreted (Davies \& 271 Blackwell, 2007; Hutchinson et al., 2007), thus saving energy. Haliotis discus hannai exhibits 272 MTF in the non-reproductive season, suggesting a possible energetic saving. Unlike the mate273 search function, energy savings would accrue continuously.

274 In the future, the following hypotheses should be tested as factors driving the evolution of 275 MTF as a mate searching strategy. First is that the functional persistence period of trail mucus 276 affects the encounter rate by others. The model's persistence period of mucus trail was set 277 following observational studies showing that mucus is degraded by bacteria within a day (Herndl 278 \& Peduzzi, 1989; Peduzzi \& Herndl, 1991). However, the trail mucus in H. asinina could 279 potentially remain on the substrate and be functional for as long as a week (cited as an 280 unpublished observation in Kuanpradit et al., 2012). If the mucus has such a long functional 281 period, abalones could encounter the trails of others much more frequently, which could enhance 282 the distance-reducing effect between opposite sexes. The second hypothesis is the effect of 283 abalone density on the efficiency of MTF behavior. It is possible that abalones are less likely to 284 find the mucus trail of other individuals at low population density, and vice versa. Although the 285 density of abalones was set 1.0 individuals $\mathrm{m}^{-2}$ in the model, the density varies by year in wild 286 populations (Ohmura et al., 2015). Therefore, the efficiency of MTF behavior could vary by year 287 in the real world, and this should be a focus for future work. In this study, expression of MTF 288 behavior is determined by allele $D$ and $d$, with nonoverlapping generations; however, the actual 289 relationship between MTF and allele is not clear, and H. discus hannai undergoes repeated 290 spawning for several years. An improved model to address these problems is needed to 291 understand the evolution of MTF behavior. 


\section{Conclusions}

294 This study indicates that trail mucus affects the direction of movement in H. discus hannai.

295 Additionally, the possibility that MTF behavior has evolved as a mechanism to increase the 296 fertilization rate was indicated by the IBM. Our simple genetic models indicate that increased

297 fertilization rates are not an evolutionarily stable driving force of MTF because the $D$ allele, 298 which determines the behavior, was 47 out of 100 simulated populations. Thus, an additional and 299 possibly additive mechanism is required to explain the fixity of the trait in natural populations. 300 H. discus hannai individuals follow conspecific mucus trails irrespective of the reproductive 301 season or sexes, supporting the possibility of the presence of other evolutionary driving forces 302 acting on the trait.

303 Estimating the extent of aggregation and nearest neighbor distance is important for the 304 population management of Haliotis species (Button, 2008) because these factors affect egg 305 fertilization rate (Babcock \& Keesing, 1999). Aggregation patterns in wild populations of 306 Nodilittorina unifasciata can be modeled using a process in which individuals follow the mucus 307 trails of others, rather than a process in which individuals remain in a preferred spot on a rock 308 (Stafford, Davies \& Williams, 2007). An IBM based on MTF behavior might be helpful for 309 predicting aggregations of $H$. discus hannai, however, location preferences based on the 310 environmental characteristics might similarly affect the aggregation. Location preferences and 311 benefits based on environmental characteristics should be studied in wild populations to help 312 parameterize future iterations of IBMs to assist in practical population management.

\section{References}

314 Babcock R, Keesing J. 1999. Fertilization biology of the abalone Haliotis laevigata: laboratory 315 and field studies. Canadian Journal of Fisheries and Aquatic Sciences 56: 1668-1678. DOI: $316 \quad 10.1139 /$ f99-106.

317 Baird RC, Jumper GY. 1995. Encounter models and deep-sea fishes: numerical simulations and 318 the mate location problem in Sternoptyx diaphana (Pisces, Sternoptychidae). Deep-Sea 319 Research Part I: Oceanographic Research papers 42: 675-696. DOI: 10.1016/0967320 0637(95)00022-X. 
321 Berec L, Angulo E, Courchamp F. 2007. Multiple allee effects and population management.

322 Trends in Ecology and Evolution 22: 185-191. DOI: 10.1016/j.tree.2006.12.002.

323 Button CA. 2008. The influence of density-dependent aggregation characteristics on the

324 population biology of benthic broadcast-spawning gastropods: pink abalone (Haliotis

325 corrugata), red abalone (Haliotis rufescens), and wavy turban snails (Megastraea undosa).

326 UC San Diego: California Sea Grant College Program. Retrieved from

327 https://escholarship.org/uc/item/4xk8j75t.

328 Calabrese JM, Fagan WF. 2004. Lost in time, lonely, and single: Reproductive asynchrony and 329 the allee effect. The American Naturalist 164: 25-37. DOI: 10.1086/421443.

330 Chapman MG. 1998. Variability in trail-following and aggregation in Nodilittorina unifasciata

331

332

333

334

335

336

337

338

339

340

341

342

343

344

345

346

347

348

349

350

351 Gray. Journal of Experimental Marine Biology and Ecology 224: 49-71. DOI: 10.1016/S0022-0981(97)00169-X.

Claereboudt M. 1999. Fertilization success in spatially distributed populations of benthic freespawners: a simulation model. Ecological Modelling 121: 221-233. DOI: 10.1016/S03043800(99)00080-0.

Coates JH, Hovel KA. 2014. Incorporating movement and reproductive asynchrony into a simulation model of fertilization success for a marine broadcast spawner. Ecological Modelling 283: 8-18. DOI: 10.1016/j.ecolmodel.2014.03.012.

Davies MS, Beckwith P. 1999. Role of mucus trails and trail-following in the behaviour and nutrition of the periwinkle Littorina littorea. Marine Ecology Progress Series 179: 247257. DOI: $10.3354 / \operatorname{meps} 179247$.

Davies MS, Blackwell J. 2007. Energy saving through trail following in a marine snail. Proceedings of the Royal Society B: Biological Sciences 274: 1233-1236. DOI: 10.1098/rspb.2007.0046.

Davies MS, Hawkins SJ. 1998. Mucus from marine molluscs. In: Advances in Marine Biology. 34: 1-71. DOI: 10.1016/S0065-2881(08)60210-2.

Erlandsson J, Kostylev V. 1995. Trail following, speed and fractal dimension of movement in a marine prosobranch, Littorina littorea, during a mating and a non-mating season. Marine Biology 122: 87-94. DOI: 10.1007/BF00349281.

Herndl GJ, Peduzzi P. 1989. Potential microbial utilization rates of sublittoral mucus trails gastropod. Limnology and Oceanography 34: 780-784. 
352 Hutchinson N, Davies MS, Ng JSS, Williams GA. 2007. Trail following behaviour in relation to

353

354

355

356

357

358

359

360

361

362

363

364

365

366

367

368

369

370

371

372

373

374

375

376

377

378

379

380

381 pedal mucus production in the intertidal gastropod Monodonta labio (Linnaeus). Journal of Experimental Marine Biology and Ecology 349: 313-322. DOI: 10.1016/j.jembe.2007.05.019.

Johannesson K, Saltin SH, Duranovic I, Havenhand JN, Jonsson PR. 2010. Indiscriminate males: mating behaviour of a marine snail compromised by a sexual conflict? PLoS ONE 5: 1-7. DOI: 10.1371/journal.pone.0012005.

Jumper, GY, Baird RC. 1991. Location by olfaction: a model and application to the mating problem in the deep-sea hatchetfish Argyropelecus hemigymnus. The American Naturalist 138: 1431-1458. DOI: $10.1086 / 285295$.

Kawata M. 1989. A view of evolutionary theory. Tokyo, Kinokuniya Company Ltd., 1989. (in Japanese)

Kuanpradit C, Stewart MJ, York PS, Degnan BM, Sobhon P, Hanna PJ, Chavadej J, Cummins SF. 2012. Characterization of mucus-associated proteins from abalone (Haliotis) candidates for chemical signaling. The FEBS Journal 279: 437-450. DOI: 10.1111/j.17424658.2011.08436.x.

Levitan DR, Sewell MA, Chia F. 2016. How distribution and abundance influence fertilization success in the sea urchin Strongylocentotus Franciscanus. Ecology 73: 248-254.

Lundquist CJ, Botsford LW. 2004. Model projections of the fishery implications of the allee effect in broadcast spawners. Ecological Applications 14: 929-941. DOI: 10.1890/02-5325.

Nakashima Y. 1995. Mucous trail following in 2 intertidal nudibranchs. Journal of Ethology 13: 125-128. DOI: 10.1007/BF02352571.

Ng TPT, Davies MS, Stafford R, Williams GA. 2011. Mucus trail following as a mate-searching strategy in mangrove littorinid snails. Animal Behaviour 82: 459-465. DOI: 10.1016/j.anbehav.2011.05.017.

Ng TPT, Saltin SH, Davies MS, Johannesson K, Stafford R, Williams GA. 2013. Snails and their trails: the multiple functions of trail-following in gastropods. Biological Reviews 88: 683700. DOI: $10.1111 /$ brv.12023.

Ohmura T, Saido T, Musashi T, Horii T, Takami H. 2015. Relationship between 1+ age juvenile and adult densities of ezo abalone Haliotis discus hannai, Iwate Prefecture, Japan. Bulletin 
382

383

384

385

386

387

388

389

390

391

392

393

394

395

396

397

398

399

400

401

402

403 of Iwate Prefectural Fisheries Technology Center 8: 17-24. (in Japnase with English abstruct).

Peduzzi P, Herndl GJ. 1991. Mucus trails in the rocky intertidal: a highly active microenvironment. Marine Ecology Progress Series 75: 267-274. DOI: 10.3354/meps075267.

Roberts R. 2001. A review of settlement cues for larval abalone (Haliotis spp.). Journal of Shellfish Research 20: 571-586.

Sims DW, Humphries NE, Bradford RW, Bruce BD. 2012. Lévy flight and brownian search patterns of a free-ranging predator reflect different prey field characteristics. Journal of Animal Ecology 81: 432-442. DOI: 10.1111/j.1365-2656.2011.01914.x.

Stafford R, Davies MS, Williams GA. 2007. Computer simulations of high shore littorinids predict small-scale spatial and temporal distribution patterns on rocky shores. Marine Ecology Progress Series 342: 151-161. DOI: 10.3354/meps342151.

Strain EMA, Johnson CR, Thomson RJ. 2013. Effects of a range-expanding sea urchin on behaviour of commercially fished abalone. PLoS One 8: e73477. DOI: 10.1371/journal.pone.0073477.

Uki N, Kikuchi S. 1984. Regulation of maturation and spawning of an abalone, Haliotis (Gastropoda) by external environmental factors. Aquaculture 39: 247-261. DOI: 10.1016/0044-8486(84)90270-9.

Zhang Z. 2008. A simulation study of abalone fertilization. Journal of Shellfish Research 27: 857-864. DOI: 10.2983/0730-8000(2008)27[857:assoaf]2.0.co;2. 
Figure 1

Estimation of the mucus following rate with eight marker-tracker sex combinations in the reproductive and non-reproductive seasons.

Error bars indicate $95 \%$ confidence intervals. Numbers represent sample sizes. Abbreviations for sex combinations: $M M=$ male follows male; $F F=$ female follows female; $F M=$ female follows male, $\mathrm{MF}=$ male follows female. 


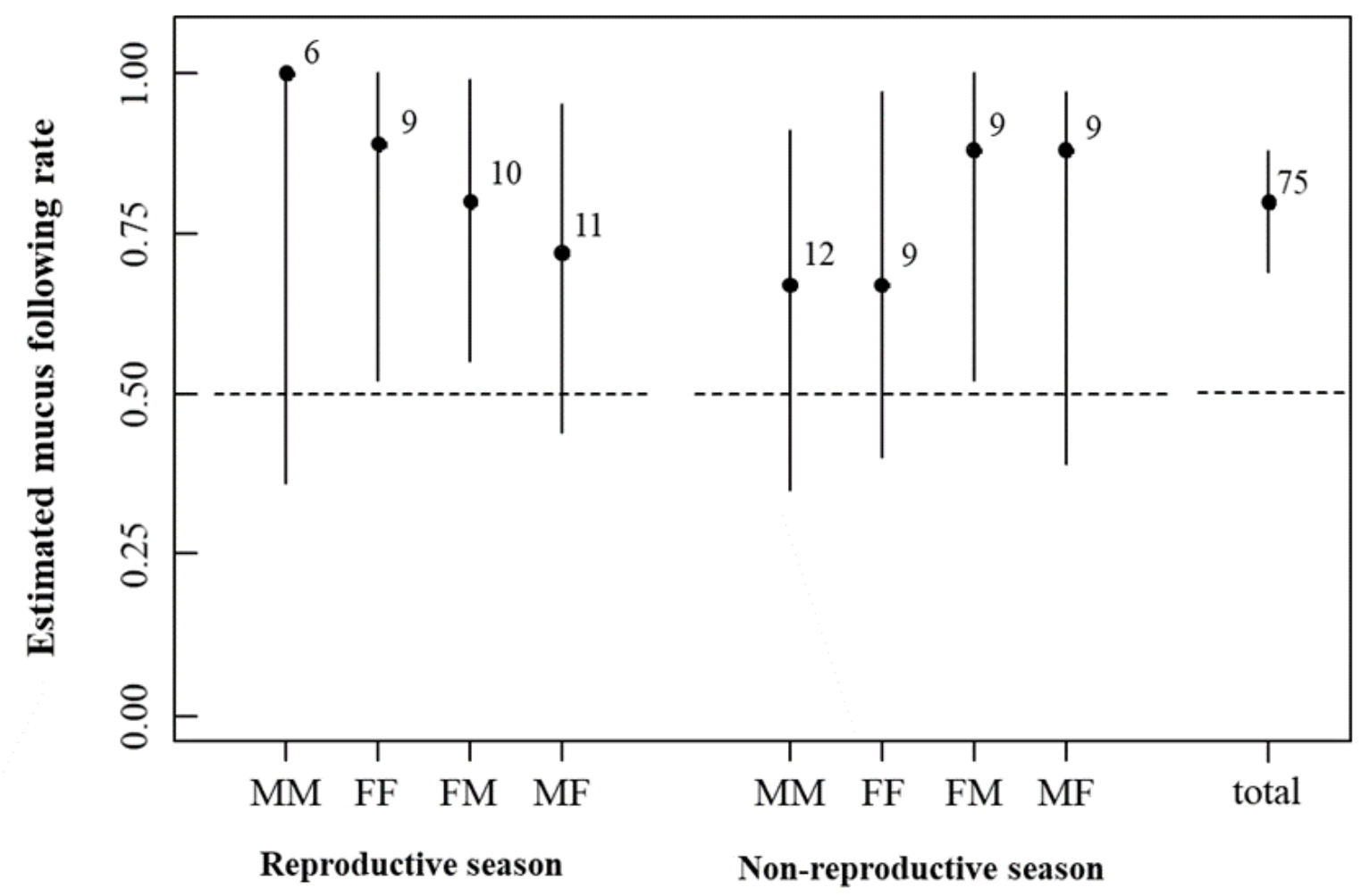


Figure 2

Dynamics of frequency of the $D$ allele in the mucus following model.

Light- and dark- colored lines correspond to simulations in which the D allele increased and simulations in which the D allele disappeared. 

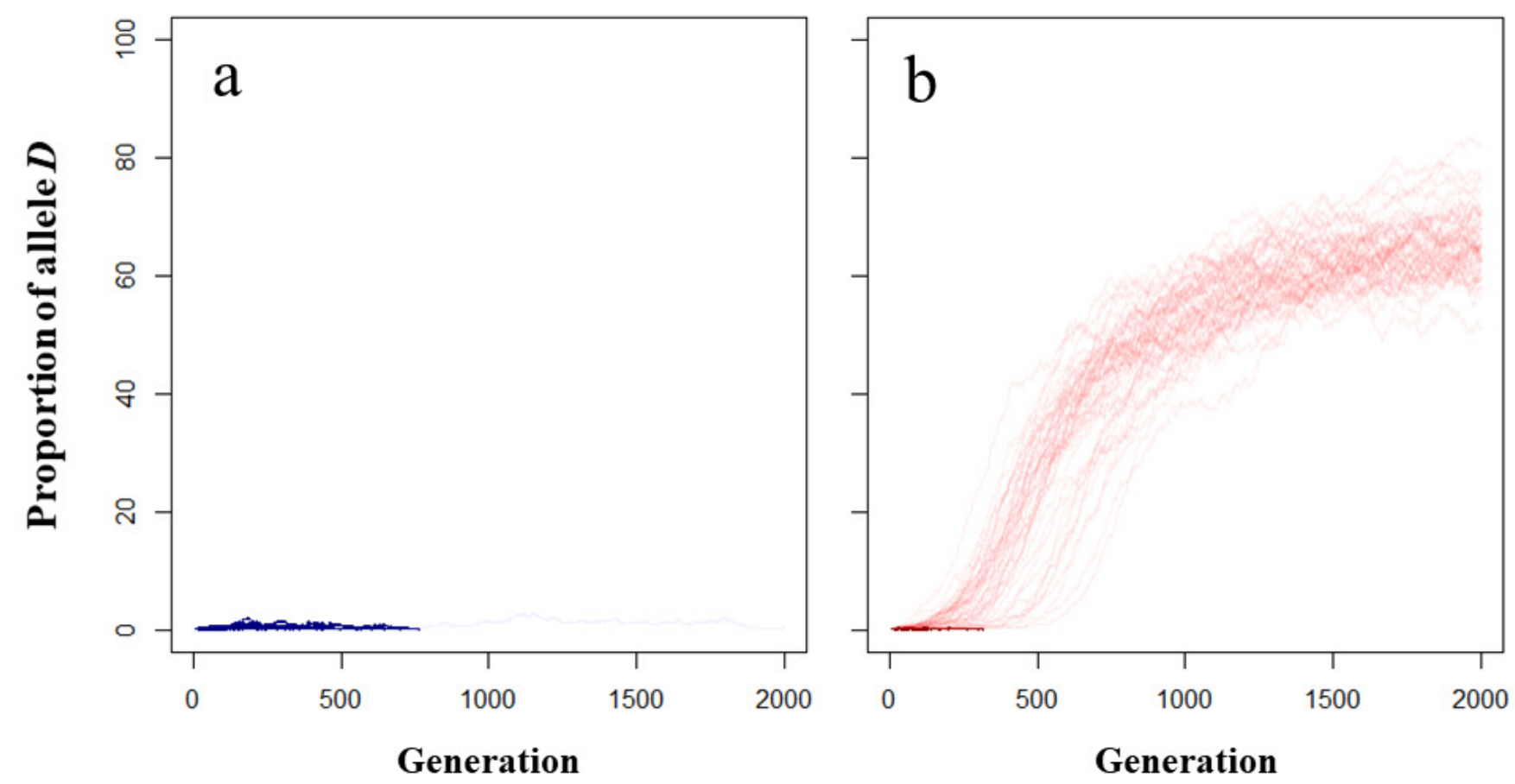